\title{
A QUEBRA DO CONTRATO E DO PRÉ-CONTRATO A PARTIR DA VIOLAÇÃO DA BOA FÉ OBJETIVA
}

\section{THE BREACH OF CONTRACT AND PRE-CONTRACT DUE TO THE VIOLATION OF OBJECTIVE GOOD FAITH}

\author{
Paulo Brasil Dill Soares" \\ Andreza Aparecida Franco Câmara
}

\begin{abstract}
Resumo: $O$ presente artigo versa sobre a a natureza jurídica da imputabilidade da responsabilidade no rompimento das tratativas preambulares na teoria geral dos contratos. Analisa a responsabilidade pela ruptura das negociações pré-contratuais e apontando os requisitos básicos que caracterizam tal modalidade, com destaque para $\mathrm{O}$ rompimento das relações contratuais sem justo motivo. Aponta-se a incidência do princípio da boa-fé nos período pré-negocial e contratuais.
\end{abstract}

Palavras-chave: Boa-fé objetiva. Tratativas. Contrato.

Abstract: This article focuses on legal nature of the applicability of legal liability for the breach of preliminary negotiations in the general theory of contracts. It examines the liability for the rupture of pre-contract negotiations and points out the basic requirements that characterize this modality, specially the breach of the contractual relationship without just cause. It appoints the effect of the principle of good faith in the prenegotiation and contractual phase.

Key-words: Objective good faith. Transactions. Contract.

\section{INTRODUÇÃO}

O princípio da boa-fé permeia todas as etapas contratuais, constituindose no ponto central para se imputar eventual indenização decorrente da responsabilidade pela ruptura abusiva das tratativas contratuais, tendo em vista que os pactuantes devem ter o dever de se comportar no iter negocial sob a orientação do princípio da bona fides.

O Código Civil de 2002 omitiu-se quanto às obrigações pré-contratuais,

\footnotetext{
Mestre em Direito pela Universidade Estácio de Sá/RJ. Professor de Direito no Departamento de Ciências Jurídicas e Sociais da Universidade Federal Rural do Rio de Janeiro - UFRRJ, no Instituto Três Rios. Pesquisador do CNPQ. Membro do Instituto dos Advogados do Brasil - IAB, nas Comissões de Direito Constitucional e Direito do Consumidor. Email: paulodillsoares1234@yahoo.com.br.

"Doutoranda em Sociologia e Direito pela Universidade Federal Fluminense. Mestre em Direito pela Universidade do Estado do Rio de Janeiro. Professora de Direito no Departamento de Ciências Jurídicas e Sociais da Universidade Federal Rural do Rio de Janeiro - UFRRJ, no Instituto Três Rios. Email: andrezaafc@hotmail.com
} 
limitando-se apenas a regular o "Contrato Preliminar", nos artigos 462 a 466. $\mathrm{O}$ contrato preliminar, exceto quanto à forma, deve conter todos os requisitos essenciais ao contrato a ser celebrado. Diferentemente do contrato preliminar que distingue-se da simples oferta ou proposta das negociações preliminares em preparo de contrato. Se o estipulante não der execução ao contrato preliminar, poderá a outra parte considerá-lo desfeito, e pedir perdas e danos.

Para haver a responsabilidade pela ruptura das negociações contratuais se faz necessário a existência da responsabilização pelo descumprimento de qualquer tipo de contrato preliminar. As partes antes de estipularem contratualmente a obrigação de constituir um contrato entre si projetado. Desse proceder, as partes criam obrigações de fazer ou deixar de fazer. Caracterizando, nesse determinado momento, um vínculo obrigacional, em que cada parte pode exigir da outra o cumprimento de uma prestação pré-firmada.

A teoria da responsabilidade pela ruptura das negociações contratuais decorre de outro campo. Os contratos se formam a partir do encontro de duas declarações receptícias de vontade, a proposta de contrato e a subseqüente aceitação. Antes, contudo, o momento em que se consagram as declarações de vontade, realizam as partes uma série de atos preparatórios. O contrato, portanto, são antecedidos por uma fase de negociação denominada atos formativos da contratação que pode perdurar no tempo, dependendo do objeto do acordo ou da natureza da gestão negocial.

O reconhecimento da responsabilidade pela ruptura das negociações contratuais requer toda a cautela por parte de operador do Direito, já que a sua configuração deve pressupor a presença de alguns elementos rígidos, sem os quais deve ser negado qualquer tipo de responsabilidade.

A fase das negociações contratuais envolve, pela sua própria natureza, uma incerteza quanto ao resultado das atividades praticadas pelas partes. Quem inicia negociações para o estabelecimento de um contrato não o faz com a certeza de que a sua atividade trará resultados. A parte que está negociando um contrato assume o risco de despender tempo e dinheiro sem obter qualquer resultado.

\section{NATUREZA JURÍDICA DA IMPUTABILIDADE NO ROMPIMENTO DAS TRATATIVAS PREAMBULARES NA TEORIA GERAL DOS CONTRATOS}

A constituição de um contrato possui como requisito fundamental o acordo de vontades para que produza efeitos jurídicos, e mesmo antes da constituição contratual existem efeitos de cunho obrigacional.

$\mathrm{Na}$ "gênese" do pré-contrato, o elemento figurativo também é a declaração de vontade que está configurada pela confiança criada na outra parte de que haverá 
efetivamente a realização de um contrato. A manifestação da vontade durante as tratativas é externalizada por uma vontade receptícia, isto é, a recepção de um contraente quanto à justa expectativa de que será firmado o contrato é essencial à eficácia do pré-negócio. Critica Pontes de Miranda (1984, p. 4) ${ }^{1}$ afirmando que a proposta durante as negociações pode não ser aceita, perdendo, portanto, a eficácia, descaracterizado estará o negócio jurídico. Contudo, se o contrário ocorre, na fase das tratativas, a oferta válida fará surgir no mundo jurídico uma gama de efeitos, podendo a mesma ser revogada.

Washington de Barros Monteiro, em sua obra atualizada por Carlos Alberto Dabus Maluf e Regina Beatriz Tavares da Silva de acordo com o atual Código Civil, trata do contrato preliminar ou pacto de contrahendo como sendo uma convenção provisória que observa os requisitos do art. 104 do Código Civil e os elementos essenciais ao contrato. Ou seja, res, pretium e consensum, objetivando a concretização de um futuro contrato definitivo, assegurando pelo começo do ajuste a possibilidade de firmá-lo no tempo oportuno (2009, p. 69 et seq.). Considera o renomado autor que o teor da Súmula 239 do Superior Tribunal de Justiça, de 28 de junho de 2000 - "O direito à adjudicação compulsória não se condiciona ao registro do compromisso de compra e venda no cartório de imóveis." -, com a nova regra dos contratos preliminares, afigurase prejudicado vez que para a exigibilidade do contrato definitivo é imperativo, preliminarmente, que o contrato tenha sido registrado no Cartório de Títulos e Documentos, nos termos do parágrafo único do art. 127 da Lei no 6.015/73, em se tratando de bem móvel; e no Registro de Imóveis tratando-se de bens imóveis (MONTEIRO, 2009, p. 71).

A prerrogativa assegurada no art. 464 do Código Civil de 2002 será obtida por meio de execução específica prevista no art. 639 do Código de Processo Civil de 1973. O Código de Processo Civil de 1939 já dispunha que: "Nas promessas de contratar, o juiz assinará prazo ao devedor para executar a obrigação, desde que o contrato preliminar preencha as condições de validade do definitivo.”

A lei $\mathrm{n}^{\mathrm{o}}$ 4.591/64, em seu art. 35, dispõe que o incorporador terá o prazo máximo de sessenta dias, a contar do termo final do prazo de carência, se houver, para promover a celebração do competente contrato relativo à fração ideal de terreno, do contrato de construção e da convenção do condomínio, de acordo com a discriminação constante da alínea "i” do art. 32. Não havendo

\footnotetext{
${ }^{1}$ Pontes de Miranda observa que "O negócio jurídico bilateral solda dois negócios jurídicos que se destinam a isto (oferta e aceitação). Por isto há efeitos próprios, típicos, da bilateralidade do negócio.”
} 
prazo de carência, conta-se da data de qualquer documento de ajuste preliminar. A boa-fé objetiva é típica das relações contratuais e pré-contratuais, exige das partes um comportamento standard, avaliando-se as atitudes de cooperação e confiança das partes e o respeito por seus interesses respectivos.

O Código Civil brasileiro de 1916 bem como o atual não adotaram a "teoria da declaração", mas a aceitação dessa teoria pela doutrina foi um dos pressupostos para a "teoria da confiança" com o objetivo de tutelar um padrão comportamental correto. A confiança que as partes depositam na consumação do negócio proposto é motivada pela boa-fé, para tanto o respeito da palavra proposta durante as negociações gera a esperança do cumprimento do que foi pactuado pela contraparte, por causa da confiabilidade da conduta, pela expectativa de um comportamento leal. Atualmente, a liberdade de contratar ou não será exercida em razão e nos limites da função social do contrato, observando os contratantes, assim na conclusão do contrato, como em sua execução, os princípios de probidade e boa-fé, conforme asseguram os artigos 421 e 422 do Código Civil de 2002.

O princípio da boa-fé objetiva é o padrão comportamental incidente nas relações pré-negociais, porque os contraentes mantêm entre si um contato mais próximo com uma finalidade comum - de constituírem um contrato.

Nessa matéria, a relação jurídica não tem por conteúdo um dever de uma parte realizar em favor da outra uma prestação. O seu conteúdo consiste em fazer surgir para as partes em negociação alguns deveres, todos decorrentes do princípio da boa-fé objetiva. Considerando-se, pacificamente, que a declaração tem um próprio valor - o valor social - autônomo, sendo o meio no qual reputa os elementos interiores reconhecíveis, nos quais o concontratante tem o direito de confiar. Devemos notar, contudo, que as despesas provenientes da confiança depositada são mantidas em um mínimo. Todavia, em todas as bases para a compensação, exceto na medida de restituição, toda confiança é compensada. Assim, a quebra da confiança imputada à outra parte pode decorrer de excessivas despesas provenientes da expectativa depositada na realização do negócio jurídico que fora frustrada no exercício abusivo de um direito potestativo.

A responsabilidade pelo rompimento das tratativas contratuais surge quando as partes negociam as cláusulas contratuais, acarretando no contraente expectativas da efetivação do pacto, devendo aquele que gerou a confiança na consumação do acordo reparar o dano caso tenha encerrado as negociações injustificadamente. 
Esse imperativo é concebido excepcionalmente, quando houver a quebra da confiança depositada nos procedimentos efetivados durante as tratativas ou, então, quando uma das partes omite informações fundamentais para que o outro contraente possa decidir sobre a realização ou não do negócio jurídico ajustado. Ou ainda, não informando sobre circunstâncias que forçosamente gerariam a invalidade contratual, pois, em regra, mesmo iniciadas as negociações, as partes têm o direito potestativo de não estabelecer o contrato não dando ensejo ao dever de indenizar.

Para alguns doutrinadores, nesta categoria Hans Stoll (1980, p. 445 et seq.), a responsabilidade pela ruptura das tratativas contratuais possui como balizamento que as negociações contraídas pelas partes irão decorrer em uma "promessa unilateral de prestar" (Einseitiges Leistungsversprechen). A responsabilidade pelo rompimento das negociações teria como pressuposto a "palavra dada” (gegebene Wort), um "sentimento comum de justiça” (KÜPPER, 1988, p. 212-6).

Para essa teoria, o fundamento da responsabilidade residiria na confiança que um dos contraentes de boa-fé deposita na efetivação do contrato, e a outra parte a partir de um comportamento culposo no momento de formação rompe produzindo prejuízos; isto ocorre porque em uma relação jurídica a confiança surge em decorrência da lei.

C. J. Goetz (1980, p. 89) criou uma fórmula de prejuízo aceitável que somente é aplicada para desencorajar as promessas ineficientes, mas isto não assegura que todas as promessas socialmente desejáveis sejam feitas. Esta é a chave para o entendimento da base dessa regra: é baseada em Pareto e não em Hicks, ou seja, promessas não recíprocas que tenham uma expectativa de valor negativo para o promissário devem ser desencorajadas, porque elas deixam o promissário potencialmente em pior situação. C. J. Goetz prossegue, então, argumentando que as coisas mudam em um contrato recíproco. Em tais circunstâncias, o custo de oportunidade de assinar um contrato é o benefício renunciado do outro (1943, p. 11).

Do ponto de vista do mercado, o custo de oportunidade provavelmente está próximo ao benefício da confiança. Por outro lado, o prejuízo da confiança provavelmente está próximo ao cumprimento total do contrato. Assim, o cumprimento total ou a expectativa de prejuízos são adequados. Além disso, quanto mais confiável uma promessa é maior o retorno que esta evidenciará, ou seja, tanto mais valiosa a remuneração. Um contrato barganhado pode oferecer às partes a oportunidade de otimizar os termos do contrato e deixar os riscos recaírem sobre o segurador do custo mínimo. C. J. Goetz (1943, p. 12) preocupa- 
se com a soma de fazer promessas, enquanto a maior parte da literatura sobre o contrato está preocupada com a decisão de quebra ou não, uma vez assinado o contrato, ou seja, depois de feita a promessa.

A teoria da promessa unilateral de prestar ou Einseitiges Leistungsversprechen não possui aceitação pela doutrina majoritária, sob o argumento de que o ato inaugural das tratativas até a efetivação do contrato não é bastante para que o contraente que efetivou uma promessa unilateral de contratar ou de não encenar as negociações sem justo motivo seja responsabilizado.

A proibição do venire contra factum proprium é o outro fundamento para a responsabilização pela ruptura das tratativas. A vedação do venire contra factum proprium encontra-se no dever decorrente do princípio da boa-fé, isto é, os deveres de conduta de natureza secundária nos quais os contraentes não devem proporcionar danos a outrem, evitando prestações positivas ou negativas para o cumprimento dos pactos.

Wofgang Küpper (1988, p. 217) ${ }^{2}$ observa que os comportamentos desleais quebram a confiança na efetivação do contrato, frustrando, assim, a expectativa do outro contratante no auxílio de manter o que foi pactuado, e, sem justo motivo desiste. Informa Francesco Benatti que (1970, p 30)

[...] a relação dirigida à conclusão de um negócio torna-se fonte da obrigação de comportar-se com boa-fé no momento em que surge para uma ou para cada uma das partes confiança objetiva na outra.

O venire contra factum proprium é uma das manifestações do princípio geral da boa-fé. Os acordos consoantes com a boa-fé surgem no direito estrito, e são justificados dogmática e sistematicamente, sendo suscetíveis de serem controlados em cada caso concreto. Nos ensinamentos de Menezes Cordeiro (1997, p. 1210), os costumes surgem quando a autonomia privada é contornada, descrevendo novos comportamentos a serem assumidos. Neste momento, encaixando a boa-fé, esta moldando os comportamentos concretos.

${ }^{2}$ Das Verbot des Selbstwiderspruches bedarf somit zwar weiterer koonkretiserung; es gibt aber als Leitidee zuglech die Richtung, in welcher die Konkretiserung zu erfolgen hat. Mit ihm kann deshalb die Haftung für das pflichtwidrige Scheiternlassen von Vertragsverhandlungen in zufriedenstellender Weise begründet werden.

${ }^{3}$ Assinala o autor que a equação proposta na literatura jurídica germânica é: relação précontratual - relação de confiança. Na Itália, "a relevância da confiança como elemento essencial do preceito ao qual está ligado o comando do art. 1.337 resulta expressamente dos arts. 1.338 e 1.398, estando, de resto implícita no próprio conceito de boa-fé objectiva reconhecida expressamente como norma dirigida à tutela da confiança de um sujeito na lealdade, na probidade, na correção de outro, com quem o primeiro entrou nas relações negociais". (Grifo nosso) 
Mais complexa, a boa-fé prescreve coordenadas a serem exigidas em respeito ao sistema jurídico. Por sua vez, a responsabilidade pela interrupção das negociações contratuais é obtida quando um dos sujeitos na relação jurídica com o seu comportamento, externaliza uma confiança na parte contrária de que o iter negocial será efetivado e ocorrerá o estabelecimento do contrato. A questão fundamental é que existe um dever geral de diligência - compreendido em sentido lato sensu -, que se coloca na fase antecedente à da execução do contrato. Dever esse movido pela confiança alcançada através do caminho negocial para que as relações econômico-sociais possam desenvolver-se com um padrão de normalidade de cada sistema. Pontes de Miranda (1984, p. 320-1) ensina que:

[...] o fundamento está em que todos têm o dever de verdade, todos, nos negócios jurídicos, hão de comunicar o que sabiam ou deviam saber, ao ser concluído o contrato. [...] Culpa in contrahendo é toda a infração do dever de atenção que se há de esperar de quem vai concluir contrato, ou de quem levou alguém a concluí-lo. O uso do tráfico jurídico cria tal dever, que pode ser o dever de verdade, o dever de diligência no exame do objeto ou dos momentos para o suporte fático, exatidão no modo de exprimir-se, quer em punctações, anúncios, minutas ou informes.

Em outro posicionamento, surge a teoria do "abuso do direito" como base para a responsabilidade pelo rompimento das tratativas. É ensinamento de Carlos Alberto da Mota Pinto (1996, p. 200):

Assentarmos, portanto, na aplicação da doutrina do abuso do direito a responsabilidade por abandono do iter negocial na fase negociatória. É essa, a nosso ver, a fórmula que, mais aceitavelmente, pode conciliar as exigências da justiça e da certeza.

A doutrina do abuso de direito como substrato da responsabilidade pela interrupção das negociações é, inicialmente, a resposta para tal questionamento, mas o seu ponto fundamental não justifica o tertium genus de responsabilidade de que se está tratando.

A tese de abuso de direito tem como fim coibir o contraente que abusa no direito de não contratar, ou seja, em dadas hipóteses o pactuante que desiste de realizar o contrato, após ter iniciado as tratativas para o seu estabelecimento. Para que se possa empregar tal teoria ao objeto sob exame, o foco de estudo desta deveria ser revertido do "direito de não contratar" para a noção do "direito de romper as negociações contratuais". Na verdade, o que se faz abusivo é o exercício do direito de romper as negociações contratuais. Para tanto, se fosse considerado abusivo o exercício do direito de encerrar as negociações em uma determinada situação seria o de se suprimir tal direito naquele caso concreto. 
O problema seria solucionado se as tratativas quando encerradas tivessem indícios ou não de abuso pelos concontratantes, verificando se o comportamento adotado feriria a confiança dirigida para a execução do objeto contratual. $\mathrm{O}$ dever de lealdade recai na exigência de que as partes pactuantes abstenhamse de comportamentos que possam mascarar o fim do negócio ou causar o desequilíbrio nas prestações previstas no tráfico negocial. Incluindo, também, o dever de atuação de modo a preservar o objetivo e a economia contratual (MENEZES CORDEIRO, 1997, p. 606-7).

Os deveres de proteção da confiança dos contraentes estão vinculados no sentido de que as partes não podem provocar danos mútuos às pessoas e aos seus respectivos patrimônios. Desse modo, os acordos devem ser protegidos, e a sua violação deverá ser interpretada consoante o princípio da boa-fé, considerando os usos do tráfico jurídico.

O fundamento da responsabilidade pela suspensão do trato negocial seria o dever de lealdade que as partes devem ter obtido através de um comportamento padronido, em consonância ao princípio da boa-fé objetiva. $O$ foco da questão reside no comportamento da parte que rompe as tratativas, durante todo o desenrolar das negociações, a fim de se verificar a congruência entre a conduta por ela adotada durante as tratativas e o ato de desistir da contratação.

Considerar que a materialidade dos fatos jurídicos é obtida a partir do classicismo com o princípio da boa-fé objetiva através do emprego da justiça distributiva e comutativa. Enquanto o princípio da confiança não exige a proteção no ordenamento jurídico em face do sistema, a materialidade da relação necessita análise sistemática protetiva. O pensamento de Menezes Cordeiro (1997, p. 1252) para solucionar tal problema é considerado da análise do caso concreto sob a ótica da boa-fé em determinada ordem jurídica.

Com base no princípio da materialidade, ou seja, a indicação de soluções para os casos concretos buscando a verdade real, a boa-fé objetiva decorrente da confiança no ordenamento jurídico afasta-se da resolução do problema do formalismo legal, visando à busca da verdade formal. Obtendo decisões que vão além do simples silogismo legal. Assim, atribuindo ao operador do direito um controle do contrato em sua materialidade, em conjunto com a confiança protegida.

O princípio da boa-fé objetiva exige das partes que considere o interesse que o outro contraente tem na conclusão do contrato, a fim de que uma parte não se comporte de maneira irresponsável em relação à expectativa do outro contratante quanto à conclusão do contrato. Por tal fato o princípio da boa-fé objetiva propicia ao juiz a matéria para formar instituições sólidas, 
correspondendo aos novos valores e fatos sociais, por meio de uma função individualizadora. Concluí Menezes Cordeiro que (1997, p. 42):

A disposição que remete para a boa-fé não tem, ela própria, um critério de decisão: a interpretação tradicional de tal preceito não conduz a nada. $\mathrm{Na}$ sua aplicação, o processo subsuntivo torna-se impossível.

O bem jurídico em proteção é a confiança depositada pelos contraentes na efetivação do que foi pactuado, nascendo de um dever de lealdade. Se um dos concontratantes desenvolve, dentro de um padrão de normalidade, a idéia de que o contrato será firmado, responderá pelos prejuízos decorrentes de seu comportamento, caso abandone as tratativas sem justo motivo. A aferição do grau de responsabilidade pelo rompimento das negociações pré-contratuais será mensurada pelo propósito e pelas condições constitutivas do contrato.

A doutrina da responsabilidade pré-contratual surge da inafastável premissa de que existem obrigações laterais, provenientes das interrupções das negociações que antecedem o contrato e tem natureza intra-obrigacional. Devido ao princípio da boafé objetiva, em seu aspecto positivo, isto é, no dever de lealdade e na proteção à confiança do contraente que teve suas expectativas quanto à manutenção do que fora acordado. Sendo na fase preambular, o contrato desfeito por mero deleite da outra parte. Na Alemanha, conforme observa Wofgang Küpper, doutrina e jurisprudência, o fundamento da responsabilidade em questão se encontra na "proteção da confiança", vedando-se, dessa forma, o venire contra factum proprium (1988, p. 31).

\section{RESPONSABILIDADE DIANTE DA RUPTURA DAS NEGOCIAÇÕES PRÉ- CONTRATUAIS: CONSIDERAÇÕES PRELIMINARES}

\subsection{O Princípio da Boa-fé Objetiva: Análise Histórica}

Mostra-se oportuno antes de aprofundarmos os estudos sobre o rompimento abusivo das tratativas pré-contratuais, abordarmos com maior atenção o princípio norteador da responsabilidade pré-negocial, e que rege todas as etapas contratuais, ou seja, a boa-fé objetiva.

O princípio da boa-fé encontra sua matriz no direito romano. A origem do vocábulo boa-fé denota, inicialmente, três vertentes semânticas, sendo a fidessacra expressão aplicada na seara religiosa; fides-fato, uso dado à clientela; e fidesética, garantia dada em um acordo. Mais tarde, acrescentou-se a expressão bona, reforçando o termo. A bona fides passou a ser utilizada na sistemática jurídica processual, no plano da concretude das ações, acrescendo-lhe o termo iudicia. A evolução do direito romanístico percorre a secularidade com o aprimoramento do princípio da boa-fé como uma cláusula geral de interpretação. 
Com o implemento do maior número de negócios surgiu a solução para harmonizar os interesses contratuais conflitantes, a inserção da cláusula contratual oportet ex fide bona que exigia além da promessa literal, a participação nos contratos sem a intenção de prejudicar o outro contratante agindo sem dolo, consoante aos padrões de lealdade e honestidade.

A inovação trazida com essa cláusula foi a maior liberdade de interpretação pelos magistrados, uma vez que deveria promover a exegese daquilo que foi prometido pelas partes, não estando restrito à letra fria da lei ou do contrato. Sendo caracterizados os primeiros indicativos da boa-fé objetiva como uma bitola na interpretação judicial, e, os primeiros apontamentos da responsabilização já na fase da promessa do pré-contrato (MENEZES CORDEIRO, 1997, p. 82).

A compilação justinianéia reviu o emprego do conceito de boa-fé, que até então, era utilizado em sua forma objetiva, para a interpretação dos contratos. Passando a seguir, o conceito de boa-fé a ser aplicado sob o aspecto subjetivista, destacadamente, nas áreas do direito de família e na posse, Menezes Cordeiro assevera o uso da boa-fé como princípio geral de direito (1997, p. 128).

No direito canônico, a boa-fé era confundida com a idéia de eqüidade, sendo dada uma atenção excessiva ao subjetivismo, principalmente em se tratando de matéria possessória, propagando-se a boa-fé no direito vulgar ${ }^{4}$. Portanto, o princípio da boa-fé, no que tange ao direito canônico, destacou-se nas pesquisas sobre os cânones éticos da boa-fé subjetiva (MENEZES CORDEIRO, 1997, p. 156). Assim sendo, a boa-fé originária do direito romanístico com seu conceito técnico-jurídico cedeu lugar no direito canônico para a retórica moral, alcançando uma dimensão axiológica própria do pensamento cristão.

O Código Civil napoleônico, em seu art. 550, considerava de boa-fé subjetiva todo aquele possuidor que detivesse a posse como se fosse proprietário, devido a um título translativo de propriedade cujos vícios ignorava. A doutrina francesa não trouxe nenhuma evolução conceitual para a boa-fé subjetiva. Menezes Cordeiro conclui que o fracasso da boa-fé no espaço jurídico e cultural francês

\footnotetext{
${ }^{4}$ A boa-fé teve uma difusão horizontal e outra vertical. Na primeira, uma expressão qualificativa de um instituto jurídico concreto passa a designar, também, um instituto diferente: é o que ocorreu quando a boa-fé passou a dar nome para uma realidade nova, como requisito na usucapião, o estado psicológico de ignorância, por parte do beneficiário. Como difusão vertical, verificou-se a evolução do bonum et aequum e da equitas de expressões técnicas para princípios de grande extensão, acabando por mesclá-los com a bona fides que, a partir de então, indica também justiça, honestidade e lealdade. $\mathrm{Na}$ vertical, portanto, comunica-se um instituto jurídico concreto a um princípio de Direito, integrando-se de molde a ampliar o significado deste.
} 
persistiu porque não aprimorou o dever de conduta; observa-se que os juristas franceses não lhe deram aplicação expressiva, pois não prosperou lá o poder criador da Jurisprudência.

O dever de lealdade decorrente da aplicação da boa-fé objetiva nos contratos surge através da interpretação da alínea 3aㅡ, do art. 1134 do Code, sendo contrária ao princípio da boa-fé subjetiva. Antes, o preceito legal era considerado um reforço para que as partes agissem durante as convenções de boa-fé.

No direito germânico, a boa-fé se desenvolveu como um elemento afetivo exterior (COUTO E SILVA, 1980, p. 162). No direito alemão, o princípio da bona fides foi estudado inicialmente, no plano jurisprudencial, através da expressão Treu und Glauben (COUTO E SILVA, 1980, p. 166). ${ }^{5}$

Conforme já abordado na introdução desse trabalho, o termo guter Glauben designa o princípio da boa-fé subjetiva, enquanto a expressão Treu und Glauben significa boa-fé objetiva. Modernamente, o termo Treu ou Treue indica o dever de lealdade, enquanto a fórmula Glauben ou Glaube designa crença. Menezes Cordeiro salienta que a expressão Treu und Glauben adquiriu uma total autonomia, significando o dever de lealdade existente entre as partes.

Strätz (apud MENEZES CORDEIRO, 1997, p. 160-70) informa que no ano de 1346 surgiu pela primeira vez a fórmula Treuwe und gelawen. A abstração do conteúdo da boa-fé tornou-se impossível de ser identificável, devido ao emprego variado da expressão que tanto designava a confiança e a boa-fé, em seu aspecto psicológico-subjetivo, como confiança e credibilidade e como credibilidade e bitola de comportamento. Menezes Cordeiro conclui que somente através da codificação se consolidou o princípio da boa-fé objetiva, prevalecendo o significado de Treu und Glauben como credibilidade e parâmetro de comportamento contratual (1997, p. 170).

Menezes Cordeiro preleciona que o desenvolvimento conceitual da boa-fé no direito alemão reassumiu o conteúdo do instituto canônico do juramento de honra, através do dever de garantir a manutenção e o cumprimento da palavra dada. Strätz (apud MENEZES CORDEIRO, 1997, p. 174-5) apresenta que nas negociações comerciais o conteúdo da boa-fé seria o cumprimento dos deveres assumidos. Salienta o mesmo autor que a boa-fé alemã apresenta duas características principais como bitola geral de comportamento no tráfego jurídico:

\footnotetext{
${ }^{5}$ A referida fórmula, além de outras fórmulas pares com conteúdo jurídico, tem a propriedade de reforçar o sentido comum dos pares, ou de alterar o sentido de um deles, em função do outro, quando comportem significados diferentes, ou, ainda, de constituir uma expressão completamente nova.
} 
o primeiro aspecto versa sobre a obrigação de cumprir os deveres inerentes ao contrato, a lealdade ao contrato, e o segundo quanto à necessidade jurídica de exercitar os direitos que interessam a outra parte. Portanto, com o cumprimento de tal exercício, desapareceria o primeiro aspecto, conforme afirma Strätz.

Menezes Cordeiro elucida que a boa-fé alemã fez emergir uma série de valores novos trazidos da Idade Média, tais como, a honra, a lealdade e o respeito ligado às juras solenemente proferidas, e outros aspectos do direito romano. Tendo como traços fundamentais objetividade e racionalismo. Decorre a afirmação de Menezes Cordeiro que a bona fides germânica obteve sua objetivação devido ao racionalismo, este sendo um efetivo elemento (1997, p. 176).

O Pandectismo elaborou críticas negativas sobre a boa-fé, em especial Savigny, em sua obra, fez referência à boa-fé como meramente ingênuo-antiquada, na expressão de Fikentscher. Contudo, a jurisprudência alemã comercial reafirmou a boa-fé como um princípio. A acepção objetiva da boa-fé no direito alemão apesar de utilizar-se na área comercial, não teve o seu emprego aceito no âmbito civilístico, se desenvolvendo paralelamente o significado objetivo e subjetivo. A boa-fé objetiva passa a exprimir um exercício das posições jurídicas, uma fórmula de interpretação objetiva dos contratos ou, até, uma fonte de deveres, independentemente do fenômeno contratual (MENEZES CORDEIRO, 1997, p. 317).

O Código Comercial alemão, de 1861, seguiu os contornos inaugurais trazidos pelas Cortes germânicas, sendo pouco referido pela doutrina. Como já dito, um dos importantes papéis da unificação do direito comercial alemão foi a manutenção da aplicabilidade da boa-fé objetiva como fonte de normas de conduta, delimitação ao exercício de posições jurídicas, elemento de reforço da ligação obrigacional e paradigma de interpretação dos negócios jurídicos.

$\mathrm{Na}$ gestão de negócios encontramos uma hipótese elucidativa, na qual o conteúdo do negócio jurídico é formado diretamente pelos deveres da boa-fé. Assim como nas relações jurídicas profissionais e artísticas o objeto do acordo é um resultado pretendido que pode ser alcançado ou não, o que se exige é que a boa-fé objetiva esteja presente em todas as ações e omissões dos pactuantes.

Os deveres laterais têm outras fontes de origem como a lei e a convenção negocial, não incidem sobre o cumprimento da obrigação ou dos deveres principais para a realização dos interesses dos negociantes (COSTA, 1994, p. 5960). Almeida Costa cita como deveres laterais: cuidado, previdência e segurança, aviso e informação, notificação, cooperação, proteção e cuidado relativos à pessoa e ao patrimônio da contraparte (1994, p. 60) .

Alguns diferem as duas modalidades de boa-fé; a boa-fé subjetiva exige das partes em negociação um conhecimento anterior ao comportamento adotado 
que viole os deveres genéricos e despersonalizados, enquanto o primado da boa-fé objetiva deve ser investigado in concreto. Evidentemente que podem ocorrer casos em que mesmo sendo realizada a prestação a contraparte seja lesada (COUTO E SILVA, 1980, p. 57) ${ }^{7}$. Isto porque a violação pode incidir no dever de lealdade entre as partes. Menezes Cordeiro considera que o princípio da boa-fé objetiva como cláusula geral foi aceita pelo uso mercantil mesmo não sendo positivada pelo Código Comercial de 1861 (MENEZES CORDEIRO, 1997, p. 60-1).

O Tribunal Comercial alemão, em $1^{1}$ de outubro de 1879 , proferiu diversos julgados incorporando o princípio como cláusula geral na esfera privada. Menezes Cordeiro salienta que houve a aplicação da chamada "boa-fé periférica", na jurisprudência das cortes germânicas, mas que o mesmo não foi feito pela doutrina (MENEZES CORDEIRO, 1997, p. 323).

O BGB instrumentalizou os limites distintivos entre a boa-fé: a subjetiva e a objetiva. Menezes Cordeiro, afirma que se encontra na doutrina germânica a diferenciação de terminologia, afastando as duas noções (MENEZES CORDEIRO, 1997, p. 327). Coube aos pandectistas apresentarem, ao examinar a segunda codificação, a diferenciação entre a bonae fidei iudicia e a boa-fé objetiva.

O Código Civil alemão pela primeira vez estabeleceu como cláusula geral a boa-fé objetiva, seguindo as orientações das Cortes que já vinham decidindo a esse respeito (MENEZES CORDEIRO, 1997, p. 329-30); porém, limitou o alcance da boa-fé. Este princípio apresenta raízes jusracionalistas claras e com uma projeção límpida no domínio do pensar liberal. A boa-fé objetiva tornou-se motivo de fortalecimento e de materialização do contrato, ou seja, a boa-fé como necessidade de cumprimento efetivo dos deveres contratuais assumidos, por oposição a cumprimentos formais, que não levam em conta o seu conteúdo verdadeiro.

O sentido inicial da boa-fé no BGB órbita em torno destes dois centros: a boa-fé subjetiva que constitui um expediente técnico para exprimir, em situações complexas, elementos atinentes ao sujeito; a objetiva que traduz o reforço material do contrato. Para Menezes Cordeiro, adotou-se um sistema aberto capaz de pôr desenvolvimentos internos ou externos, responder a problemas impensáveis

${ }^{6}$ Mário Júlio de Almeida Costa exemplifica como dever lateral a obrigação do locatário de logo avisar o locador, sempre que cheguem ao seu conhecimento vícios da coisa, ou saiba que a ameaça algum perigo ou que terceiros se arrogam direitos sobre ela, quando o facto seja ignorado pelo locador. Do mesmo modo, ao operário, que tem como dever principal a perfeita realização da tarefa definida no contrato de trabalho, compete o dever lateral de velar pela boa conservação dos maquinismos.

${ }^{7}$ Couto e Silva mencionou-o como o princípio fundamental para a construção do que parece ser "o direito comum europeu". 
quando da codificação. Pelo que, na boa-fé foi centrada a capacidade reprodutora do sistema, pois dotada aquela de um peso jurídico e cultural capaz de dar credibilidade às soluções encontradas (MENEZES CORDEIRO, 1997, p. 331).

Encontramos no apogeu do liberalismo a consagração do princípio da boa-fé (COUTO E SILVA, 1980, p. 46). O Código Civil alemão, em seu § 242, previu que o devedor é obrigado a realizar a prestação do modo como o exige a boa-fé levando em conta os usos de tráfico, igualmente o $\S 157 \mathrm{faz}$ a previsão de que os negócios jurídicos devem ser interpretados de acordo com a boa-fé ${ }^{8}$. Como resultado surge a aplicação do princípio da boa-fé, e a compreensão científica dos deveres laterais ou anexos surge a partir de uma fonte autônoma de direitos e obrigações.

A doutrina representada por Clóvis do Couto e Silva entende que a definição clássica de relação obrigacional vem se aproximar daquela encontrada também no modelo da common law, refletindo-se no hábito de decidir pela concreção das normas abertas. A relação obrigacional cria um vínculo dialético e polêmico, entre devedor e credor, pela presença de elementos de cooperação necessários ao adimplemento das partes envolvidas nas negociações (COUTO E SILVA, 1980, p. 47). O mesmo autor reconhece o papel restritivo da boa-fé em relação à autonomia da vontade. Destaca que o aspecto capital para a criação judicial é o fato de a boa-fé possuir um valor autônomo, não relacionado com a vontade, a boa-fé fixaria as regras para o negócio, permitindo que os contraentes possam controlar os atos lesivos.

Não houve o fim da autonomia da vontade, pois as partes possuem liberdade para negociarem, já que em princípio as tratativas iniciais das negociações não geram a obrigação de efetivar a posterior contratação, entretanto existirá a responsabilização pela ruptura pré-contratual em situações excepcionais.

A teoria da responsabilidade objetiva no campo da responsabilidade précontratual pela ruptura das negociações contratuais não foi acolhida pelas legislações contemporâneas. A segurança jurídica e a busca da decisão justa são os escopos dos sistemas jurídicos modernos, e a admissão da responsabilidade objetiva levaria aos sujeitos que impulsionassem as tratativas e rompessem sem justificativa.

Récio Eduardo Cappelari diverge da doutrina objetiva, não pelas mesmas razões invocadas por Planiol, Ripert e Antônio Chaves, que se basearam na teoria da culpa pelo rompimento das negociações. Cappelari se opõe, em primeiro lugar, porque seria injustificável como solução proclamar a responsabilidade, em todos os casos de ruptura da fase pré-contratual. Em segundo lugar, porque se adotando o modelo da responsabilidade objetiva se conferiria às partes uma

${ }^{8} \mathrm{O} \S 157$ do BGB dispõe nesse sentido: "Os contratos devem ser interpretados do modo como o exigir a boa-fé, tomando-se em consideração os usos de tráfico.” 
segurança superior àquela de que desfrutam no interior dos contratos. Em terceiro lugar, poderia conduzir a uma diminuição acentuada das contratações (1995, p. 42). Cappelari admite a responsabilidade objetiva pré-contratual quando se tratar de responsabilidade do menor e do preposto.

Alguns autores divergem de Cappelari, quando menciona que os casos de responsabilidade pré-contratual do menor e do preposto configurariam hipóteses de responsabilidade subjetiva pela interrupção das negociações contratuais. $\mathrm{Na}$ opinião de Cappelari, esse tipo de responsabilidade sempre vai exigir a culpa do agente, mesmo quando ele seja menor ou preposto. A aplicação da responsabilidade civil objetiva não pode ser confundida com a boa-fé objetiva. Nos casos indicados trata-se de responsabilidade civil objetiva por ato de terceiros $(1995$, p. 42).

Manifesta Esser que a atuação do princípio da boa-fé deve circundar também as cláusulas gerais para a manutenção da segurança jurídica (ESSER, 1961, p. 83): "Por esto debemos habituarnos a utilizar las cláusulas generales, com topoi tales como 'buena fe', en calidad de autorización para la creación judicial de instituciones.”

A quebra das obrigações secundárias de conduta manifesta-se em consonância ao princípio da boa-fé, através de categorias genéricas externalizadas a partir do dever de lealdade e cooperação e de categorias específicas como informação, confiança, fidelidade, compromisso, capacidade de sacrifício e auxílio de uma parte a outra. Contudo, a violação dessas categorias será ensejada pela culpa lato sensu, que no caso da responsabilidade do pré-contrato se dá através da inobservância dos deveres inerentes à exigência de comportamento segundo a boa-fé. A doutrina entende não ser possível a responsabilização pela ruptura das tratativas, quando o fato motivador da ruptura não puder ser imputado ao agente.

A culpa não é o único elemento configurador da responsabilidade pela ruptura do pré-contrato. Sabemos que a culpa lato sensu, no âmbito da responsabilidade civil aquiliana, estará caracterizada quando um dever comportamental de natureza social for violado, isto é, há intenção de produzir um dano a outrem. Outra hipótese prevista na ordem jurídica é da responsabilidade extracontratual, prevendo o caso de violação involuntária de bens jurídicos alheios, através da modalidade de culpa stricto sensu, por meio de um ato negligente e/ou imprudente, havendo uma inobservância de um dever de cuidado, ou, por ato voluntário sem a existência de um vínculo contratual.

A responsabilidade pela interrupção das tratativas se caracteriza através da concreção dos conceitos de dolo e culpa stricto sensu. É impossível a mera transposição conceitual de culpa da responsabilidade extracontratual para se solucionar os debates travados no que tange à responsabilidade pré-contratual. 


\subsection{Existência de Negociações como Requisito para a Responsabilização pelo Rompimento das Relações Pré-contratuais}

O requisito fundamental para a responsabilidade pelo rompimento do précontrato advém da concepção de que já estar caracterizada uma negociação précontratual que enseja a expectativa nas partes de firmarem o negócio. $\mathrm{O}$ acordo de duas ou mais vontades se faz necessário para que ocorra uma relação jurídica contratual. Mota Pinto acentua que os contratos não são criados no mundo dos fatos, e sim no mundo jurídico por "geração espontânea”. A sua constituição é contextualizada de um processo genético, podendo ser simples ou complexos, de acordo com cada caso fático. De tal sorte, que os contratos, independente de sua complexidade, necessitam de uma fase preambular (COSTA, 1994, p. 165).

Nesse contexto, é importante ressaltar que não é qualquer tipo de tratativa que ensejará a responsabilização pela ruptura do pré-contrato. $\mathrm{O}$ pacto que permite a responsabilização do contratante é aquele que leve as parte a ter "uma razoável base de confiança”, conforme lembra Mário Júlio de Almeida Costa (1994, p. 54).

A extensão, o conteúdo e a duração das tratativas podem sofrer variações em cada caso concreto. O iter negocial na fase da constituição do contrato acaba levando à formação de uma relação jurídica contratual. Para tanto, certos contratos necessitam apenas de negociações para que haja a aderência do oblato à oferta efetivada pelo policitante 9 . Leciona Carlos Alberto Mota Pinto (1996, p. 166-7) que:

o momento de perfeição do contrato é antecedido e preparado por actos de caráter dispositivo. Todos têm em vista, como escopo último, a conclusão definitiva, embora cada um deles vise a um objectivo imediato e específico, instrumental em relação ao fim último visado. Como cada acto preparatório visa superar um obstáculo ao acordo contratual e tornar este, progressivamente, mais fácil, o processo de gestação do negócio, com um ponto donde se parte e uma meta a alcançar, sugere a imagem dum caminho, dum trajecto, duma via a percorrer. Por isso, aparece, tantas vezes, designado e nós manteremos a tradição, por iter negocial.

Nos contratos complexos ocorre um sucedâneo de subfases durante as tratativas, como a troca de informações sobre o objeto contratual, a análise da viabilidade do mesmo objeto, os custos operacionais do futuro negócio, que em certos contratos vão desde pesquisa de mercado até a contratação de terceiros, discussão de resultados iniciais com as devidas ponderações de cada parte. A iniciativa da parte contrária em elaborar uma proposta concreta de acordo

${ }^{9}$ Por exemplo, a situação em que uma pessoa vê na vitrina de uma loja um roupa exposta à venda, com seu preço fixado. Para realizar o contrato, basta apontar para o vendedor o objeto pretendido e pagar preço. As negociações se dão em âmbito bastante restrito, limitando-se à oferta e à aceitação pura e simples. 
com a vontade de realizar o contrato, e, por fim, a efetiva proposta tendo por base um padrão jurídico, que dependerá do aceite do outro contratante para ingressar na fase da execução.

A responsabilidade civil pela interrupção dos acordos pré-contratuais decorre da violação de deveres de conduta assumidos pelos contraentes ao firmarem as tratativas que irão constituir os contratos. Para tanto, cumpre delinear que a responsabilização pela ruptura das tratativas em contratos de maior complexidade será regida pela boa-fé em sentido positivo, na lição de Menezes Cordeiro (1997 p. 1299) "[...] traduz, no caso concreto, a projecção dos dados materiais relevantes do sistema, a cuja luz deve ser vista a confiança e a materialidade da regulação jurídica”.

O dever de diligência pode ser resumido pelo comportamento com o justo esforço ou com a colaboração exigível em cada caso concreto para com o devedor, no cumprimento de suas obrigações, neste caso, as de natureza secundária. A diligência remete a um comportamento claro, conciso e simples, ou nos dizeres do BGB, $\S 276$, ao "cuidado necessário no tráfego". Existem casos, entretanto, em que as partes estão lado a lado com boa-fé subjetiva, mas lhes falta a diligência exigida pelo sistema jurídico.

$O$ trato negocial que não visa materialidade jurídica e não gera na contraparte a confiança na conclusão do que foi negociado não será objeto de responsabilização caso seja rompido. Porém, no caso da ocorrência de tratativas contratuais que se firmam a partir de uma "atividade comum", "destinada à análise e elaboração do projecto de negócio”, como acentua, Mário Júlio de Almeida Costa (1996, p. 54) se criam deveres e direitos mútuos.

Somente com a análise de cada caso concreto é que se efetiva a existência de tratos contratuais, ou seja, aqueles que ensejam deveres jurídicos de lealdade e de confiança. Através da aferição das provas in concreto é que chegaremos ao alcance e a profundidade das negociações. O comportamento standard exigível é aquele em que os contraentes incutem, durante as negociações, a confiança na realização do negócio e que deverá ser mantido até a sua efetivação.

O pressuposto de existência das tratativas será averiguado quando estas forem travadas com qualidade, independendo do número de atos praticados durante as negociações. Isto é, para a responsabilidade pelo rompimento dos acordos pré-contratuais é necessário que haja a confiança no tráfico jurídico do negócio jurídico, assim, quanto maior a confiança na realização do objeto contratual maior será a projeção do contrato, e, por conseguinte, maior será a responsabilização da interrupção imotivada. Deve-se, considerar, também, a expectativa econômica criada pela futura realização do negócio. Se o promitente tem uma idéia da probabilidade 
subjetiva que ele desempenhará naquela tratativa, então sua avaliação da expectativa do valor da promessa para o promissário é o benefício da confiança, e a ruptura sem justo motivo acarreta o prejuízo da confiança.

Um direito contratual eficiente exigiria que o promitente tivesse idéia do efeito sobre o promissário. Isto pode ser conseguido, de acordo com C. J. Goetz (1980, p. 1266), fazendo com que a expectativa do valor dos prejuízos seja igual à perda do promissário. Observamos que os prejuízos não são iguais àqueles causados pela perda da confiança depositada pelo promissário. Existe uma dedução relacionada ao benefício da confiança do promissário, desencorajando-o a fazer promessas com baixa probabilidade subjetiva de compensação que não serão efetivamente realizadas.

Quando a promessa é mantida, ela consegue os benefícios projetados, ao contrário, se rompida sem motivo justo, arcará aquele que interrompe com alguns custos mais o pagamento do prejuízo. A expectativa de valor da promessa para o promissário é agora a expectativa de valor da sociedade.

É possível aferir o grau de confiança que as partes depositam na conclusão contratual, mediante parâmetros objetivos sobre o quantum que se emprega na constituição do negócio (KÜPPER, 1988, p. 34). Para a responsabilização pré-contratual, não se exige a presença de todos os pressupostos da existência de negociações contratuais, bastando uma seqüência de atos inequívocos no sentido de que haverá um desfecho favorável à concretização do negócio.

A existência das negociações será atestada a partir do reconhecimento da vontade implícita de $\operatorname{contratar}^{10}$ e da confiança depositada pelas partes na validade do negócio jurídico celebrado. Se a confiança não se confirmar em decorrência dos fatos que impedem a validade ou a conclusão do contrato que podem estar ligados a elevadas despesas e avaliações de eventuais margens de lucro desaconselháveis que revelou inviável a manutenção das tratativas de um futuro negócio jurídico, não há que se falar de responsabilização pela ruptura do pré-contrato e frustração negocial.

Não se faz necessário a existência de uma oferta para se caracterizar a responsabilização pelo rompimento do pré-contrato, visto que a oferta é o modus

\footnotetext{
${ }^{10}$ Se alguém apresenta a outra pessoa um projeto, para cuja elaboração ele efetivou enormes investimentos e dedicou grande parte do seu tempo, sem que o destinatário sequer tivesse ciência de que o projeto estava sendo elaborado, este poderá evidentemente recusar o estabelecimento do contrato sem qualquer justificativa. Não porque ele não tenha consentido na realização do projeto em si, mas porque nem sequer houve início de negociações entre as partes. Não houve nem sequer oportunidade para que se iniciasse alguma atividade comum entre essas duas pessoas.
} 
operativo do acordo. Na verdade, o elemento deflagrador da responsabilidade é a quebra da confiança que uma das partes incute na outra quanto à realização do negócio. Como compreende Pontes de Miranda a configuração desse tipo de responsabilidade tem como pressuposto o dever de lealdade e honestidade no iter negocial. É de Pontes de Miranda a afirmação: “[...] todos os homens têm de portar-se com honestidade e lealdade, conforme os usos do tráfico, pois daí resultam relações jurídicas de confiança, e não são relações morais" (1984, p. 321). É fácil concluir que a oferta não é o meio necessário para que se fixem entre os contraentes o dever de lealdade, cuja infringência pode gerar a responsabilidade pré-contratual pela ruptura das tratativas.

A efetiva existência de tratativas é demonstrada pela "punctação" do contrato. Essa denominação deriva do alemão Punktation, significando aquela hipótese em que a formação contratual se dá de modo gradual, quando os contraentes manifestam sua vontade sob aspectos parciais dos termos contratuais à medida que chegam a um consenso sobre estes. Contudo, a punctação encontra seu problema quando da definição da eficácia de tais acordos parciais estabelecidos no curso das negociações. A punctação não é prova da existência do contrato, a validade das tratativas necessitará do consenso sob os elementos essenciais do contrato. A punctação é prova inequívoca, portanto, não do contrato, mas da existência de uma fase formativa.

É de senso comum que o simples fato de os contraentes terem feito minutas sobre alguns aspectos do contrato não os obriga a efetivarem sua conclusão. As partes poderão desistir da efetivação do negócio jurídico durante a fase das tratativas, sem estar configurada qualquer espécie de abuso do direito de não contratar. Os pactos parciais vinculam as partes quanto aos seus efeitos. Utilizam-se os pactos aludidos para fazer prova da existência de tratos negociais.

Por fim, as negociações são caracterizadas pela punctação que geram nos contraentes uma estabilidade, determinando a confiança na realização do contrato. A punctação será decisiva para a comprovação da presença ou ausência de comportamento de boa-fé das partes nas negociações pré-contratuais.

\section{CONSIDERAÇÕES FINAIS}

Não existe, assim, uma obrigação de contratar, decorrente de simples fato de se ter dado início às negociações. Se tal obrigação existisse, ela certamente se constituiria em um sério entrave à circulação da riqueza e ao estabelecimento de relações econômicas entre as pessoas. A liberdade para negociar, sem que pelo simples fato do estabelecimento das tratativas surja a obrigação de contratar, é fundamental para o incremento e desenvolvimento das relações econômicas. 
Não é concebível que seja considerado como requisito para o início dos pactos, a certeza no estabelecimento do contrato. Os acordos, pela sua própria natureza, pressupõem dúvidas e incertezas dos contraentes no que respeita ao estabelecimento da relação jurídica contratual.

Considerações dessa natureza é que levaram a doutrina e a jurisprudência, tanto brasileira como estrangeira, a negar, durante muito tempo, e alguns autores até hoje, qualquer tipo de responsabilidade pelo fato de um dos contraentes ter interrompido as negociações entabuladas pelas partes com a finalidade de estabelecerem relação jurídica contratual. A responsabilidade précontratual pela ruptura de negociações contratuais com o fundamento na teoria da inobservância da boa-fé durante as tratativas.

A confiança na conclusão do contrato pode ter como conseqüências maior emprego de tempo e dinheiro no projeto de contrato em andamento. Cumpridas certas etapas de negociação, cresce a probabilidade de que o negócio projetado pelas partes se realizará.

A negação da possibilidade de responsabilidade pré-contratual pela ruptura das negociações contratuais pelo fundamento de que somente se pode responsabilizar alguém no âmbito das relações contratuais e pré-contratuais quando exista entre as partes uma relação jurídica obrigacional, no sentido de haver já uma prestação a ser cumprida, implicaria em uma solução dogmática e artificial, distante da realidade dos fatos.

\section{REFERÊNCIAS}

AGUADO, Josep L. El deber de información en la formación de los contratos. Madrid: Marcial Pons, Ediciones Jurídicas y Sociales, 1996.

BENNATI, Francesco. A responsabilidade pré-contratual: com a correspondência entre os preceitos do direito italiano e do direito português. Tradução Vera Jardim e Miguel Caieiro. Coimbra: Almedina, 1970.

BREBBIA, Roberto H. Responsabilidad precontratual: evolución de la doctrina: ensayo de un sistema de responsabilidad precontractual en el derecho argentino - derecho comporado. Rosario: Victor P. de Zavalia, 1957.

CAPPELARI, Récio Eduardo. Responsabilidade pré-contratual (aplicabilidade ao direito brasileiro). Porto Alegre: Livraria do Advogado, 1995.

COMPARATO, Fábio Konder. Reflexões sobre as promessas de cessão de controle acionário. In: . Novos ensaios e pareceres de Direito Empresarial. Rio de Janeiro: Forense, 1981. 
COSTA, Mário Júlio de Almeida. Responsabilidade civil pela ruptura das negociações preparatórias de um contrato. Coimbra: Coimbra Editora, 1994.

. Aspectos modernos do direito das obrigações. In: ESTUDOS de direito civil brasileiro e português. São Paulo: Revista dos Tribunais, 1980

COUTO E SILVA, Clóvis F. A obrigação como processo. São Paulo: José Bushatsky, 1976.

. O princípio da boa-fé no direito brasileiro e português. In: ESTUDOS de direito civil brasileiro e português. São Paulo: Revista dos Tribunais, 1980.

CUPIS, Adriano de. Il danno: teoria generale della responsabilità civile. Milano: Dott A . Giuffrè, 1946.

ESSER, Josef. Principio y norma en la elaboración jurisprudencial del derecho privado. Barcelona: Bosch, 1961.

FAGGELLA, Grabielle. Dei periodi precontrattuale e della loro vera ed esatta costruzione scientifica. In: STUDI giuridici in onore di Carlo Fradda. Napoli: Luigi Pierro, 1906. Tomo III.

GARCEZ NETO, Martinho. Responsabilidade in contrahendo. Prática da responsabilidade civil. 4. ed. São Paulo: Saraiva, 1989.

GOETZ, C. J. et al. Promessas sob coação: um exame das bases do contrato. Yale: Jornal de Direito de Yale, 1980.

KÜPPER, Wolfgang. Das scheitern von vertragsverhandlungen als fallgruppe der culpa in contrahendo. Berlim: Duncker \& Humblot, 1988.

MARTINS-COSTA, Judith Hofmeister. Sistema e cláusula geral: a boa-fé objetiva no processo obrigacional. Tese de doutorado apresentada na Universidade de São Paulo (mimeo.), v. II, 1996.

MENEZES CORDEIRO, António Manuel da Rocha e. Da boa fé no direito civil. Coimbra: Almedina, 1997.

PONTES DE MIRANDA, Francisco Cavalcanti. Tratado de direito privado. São Paulo: Revista dos Tribunais, 1984.

MOTA PINTO, Carlos Alberto. A responsabilidade pré-negocial pela não conclusão dos Contratos. Boletim da Faculdade de Direito da Universidade de Coimbra, supl. 14, p. 143-250, 1996.

OLIVEIRA, Ubirajara Mach de. Quebra positiva do contrato. Revista de Direito 
do Consumidor, São Paulo, n. 25, p. 39-56, jan./mar. 1998.

PERLINGIERI, Pietro. Perfis de direito civil. Tradução Maria Cristina de Cicco. Rio de Janeiro: Renovar, 1997.

PEZZELLA, Maria Cristina Cereser. O princípio da boa-fé objetiva no direito privado alemão e brasileiro. Revista do Direito do Consumidor, São Paulo, n. 23/24, p. 199-224, jul./dez. 1997.

RASI, Salvatore A. La responsabilità precontrattuale. Rivista di Diritto Civile, Padova, ano 20, 1974.

RICHETER, Giorgio Stella. La responsabilitá precontrattuale. Torino: Utet Libreria, 1966.

STIGLITZ, Rubén S. Responsabilidad precontractual. Buenos Aires: Abeledo-Perot, 1992.

TOURNEAU, Philippe le. La rupture des négociations. Revue Trimestrielle de Droit Commercial et de Droit Économique, Paris, n . 3, juille/sept. 1998.

VASCONCELLOS E BENJAMIN, Antonio Herman de, et al. Comentários ao Código de Proteção do consumidor. São Paulo: Saraiva, 1991.

Artigo recebido em 05/03/11 e aprovado para publicação em 24/11/11

Como citar: SOARES, Paulo Brasil Dill; CÂMARA, Andreza Aparecida Franco. A quebra do contrato e do pré-contrato a partir da violação da boa fé objetiva. Scientia Iuris, Londrina, v. 15, n. 2, p. 9-30, dez. 2011. DOI: 10.5433/2178-8189.2011v15n2p9 